\title{
La unidad del exilio: \\ Las revistas Cuadernos de Marcha y Controversia en México
}

\author{
A unidade do exílio: \\ Revistas Cuadernos de Marcha e Controversia en México
}

Martina Garategaray ${ }^{1}$

\begin{abstract}
Resumen Este artículo se propone explorar dos revistas emblemáticas de las culturas argentina y uruguaya que se publicaron en el exilio: Cuadernos de Marcha (1979-1985) y Controversia para el examen de la realidad Argentina (1979-1981). Consideramos que las mismas son revistas que expresaron y dotaron de sentido a un momento de la historia político cultural reciente tan significativo como fue el exilio y en cuyas páginas creemos quedaron las marcas de los debates de una época que puede ser revisitada para comprender tanto a los años setenta como el devenir democrático de Argentina y Uruguay. Es nuestra hipótesis que, si el exilio fue un importante espacio de debate y reflexión, funcionó al interior de estas revistas como "mito de unidad", es decir no sólo como un lugar físico sino también simbólico que les permitió articular nuevos colectivos y categorías para interpretar la realidad. Y el modo particular de realizar estas operaciones estuvo íntimamente tensionado por sus respectivas culturas políticointelectuales.
\end{abstract}

Palabras clave revistas; exilio; Latinoamérica

Resumo Este artigo propõe explorar duas revistas emblemáticas das culturas argentina e uruguaia que foram publicadas no exílio: Cuadernos de Marcha (1979-1985) e Controversia para el examen de la realidad Argentina (1979-1981). Consideramos que as mesmas são revistas que expressaram e atribuíram um sentido a um momento da história político-cultural recente tão significativo como foi o exílio e em cujas páginas acreditamos que restaram as marcas dos debates de uma época que pode ser revisitada para compreender tanto os anos setenta como o devir democrático da Argentina e do Uruguai.É nossa hipótese que, se o exílio foi um importante espaço de debate e reflexão, ele funcionou no interior destas revistas como "mito de unidade", ou seja, não somente como um lugar físico, mas também simbólico que lhes permitiu articular novos coletivos e categorias para interpretar a realidade. E o modo particular de realizar estas operações esteve intimamente tensionado por suas respectivas culturas político-intelectuais.

Palavras-chave Revistas; Exílio; América Latina

\footnotetext{
${ }^{1}$ Investigadora del CONICET, Centro de Historia Intelectual de la Universidad Nacional de Quilmes (UNQ). Docente en la Universidad de Buenos Aires (UBA). E-mail: martugarategaray@yahoo.com.ar.
}

\section{GANPHLAC}

Revista Eletrônica da ANPHLAC, ISSN 1679-1061, No. 19, p. 186-207, jul./dez., 2015. http://revista.anphlac.org.br 
Artigo recebido em: 23/08/2015

Artigo aprovado para publicação em:15/10/2015

\section{Introducción}

En junio de 1973 Juan María Bordaberry, que había sido electo presidente por el partido colorado con un escaso margen en 1971, clausuró el parlamento en Uruguay con el respaldo de los militares en lo que se llamó un autogolpe. En Argentina, Isabel Martínez de Perón, en quien recayó la presidencia después de la muerte de Juan Domingo Perón en 1974, fue depuesta por la Junta Militar con un golpe de Estado en marzo de 1976. Así se iniciaban en estos países, las dictaduras que llevarían al exilio a artistas, intelectuales, militantes y políticos identificados como "subversivos" o "potenciales disidentes". Muchos de ellos eligieron la ciudad de México como destino y desde allí “publicaron una revista” (SARLO, 1992, p. 9).

Este artículo se propone explorar dos revistas emblemáticas de las culturas argentina y uruguaya que se publicaron en el exilio: Cuadernos de Marcha (1979-1985) y Controversia para el examen de la realidad Argentina (1979-1981) ${ }^{2}$. Consideramos que las mismas son revistas que expresaron y dotaron de sentido a un momento de la historia político cultural reciente tan significativo como fue el exilio y en cuyas páginas creemos quedaron las marcas de los debates de una época que puede ser revisitada para comprender tanto a los años setenta como el devenir democrático de Argentina y Uruguay.

Si bien algunos trabajos se han escrito sobre estas empresas editoriales, en estas páginas buscamos comparar ambas revistas a partir de la marca mítica del exilio; no nos interesa qué dicen del exilio estas publicaciones o como procesan el destierro sino, cómo juega esa situación en su interior, en el modo en el que se van posicionando frente a la situación nacional y regional y redefinen, o no, sus anteriores posiciones político intelectuales. ${ }^{3}$ Es nuestra

\footnotetext{
${ }^{2}$ Este trabajo es un avance preliminar del proyecto sobre revistas latinoamericanas en la transición democrática, que comenzó en el marco de una estancia de investigación en la Universidad de Stanford gracias a una beca Fulbright-Ministerio de Educación de Argentina. Agradezco especialmente a Jorge Ruffinelli su generosidad para conversar sobre la experiencia "Marcha”. Una versión preliminar del mismo fue presentada a las XV Jornadas Interescuelas.

${ }^{3}$ Sobre estas revistas cabe mencionar el trabajo de PINHEIRO DE PAULA COUTO (2012) que es uno de los primeros abordajes que se aproxima de un modo comparado a las revistas Cuadernos de Marcha y Controversia, y el trabajo de PONZA (2010) que se bien no se centra en Cuadernos de Marcha, al analizar las publicaciones argentinas del exilio menciona a la revista uruguaya por desplegar temáticas comunes. Sobre el exilio pueden
}

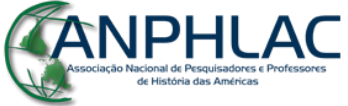

Revista Eletrônica da ANPHLAC, ISSN 1679-1061, N. 19, p. 186-207, jul./dez., 2015. 
hipótesis que, si el exilio fue un importante espacio de debate y reflexión, funcionó al interior de estas revistas como "mito de unidad", es decir no sólo como un lugar físico sino también simbólico que les permitió atravesar esos traumáticos años y ofrecer una lectura tanto del pasado reciente como del futuro. En otras palabras, creemos que el exilio mexicano fue un lugar que les permitió articular nuevos colectivos mientras procesaban su doloroso pasado reciente, construían nuevas ideas y categorías para interpretar la realidad, y redefinían sus tradiciones de pertenencia. Y el modo particular de realizar estas operaciones estuvo íntimamente tensionado por sus respectivas culturas político- intelectuales.

\section{Las revistas}

Los cambios en los modos de interpretar los documentos de la mano de los aportes de la nueva historia de las ideas y el giro lingüístico, ha transformado el estatus de las revistas: de fuentes de las que extraer alguna cita pasaron a ser consideradas empresas culturales relevantes en el debate y la legitimación político cultural. Es así que la incorporación de las revistas como objetos de estudio ha modificado el campo de los trabajos sobre el pensamiento de una época y sus intelectuales enriqueciendo las perspectivas de la historia social, política, cultural, la sociología de los intelectuales, y la historia intelectual. En este sentido varios trabajos se han preocupado por especificar su particularidad y el modo de abordarlas ${ }^{4}$. Es a partir de estos enfoques que nos proponemos leer a Cuadernos de Marcha y Controversia.

A sus jóvenes 80 años, como supo decir Ángel Rama, Carlos Quijano, publicó en México los 27 números de los Cuadernos de Marcha que cubrieron 5 ininterrumpidos años entre junio de 1979 hasta junio de 1984. Mientras Juan Carlos Onetti expresaba su "admiración y asombro por el hecho inesperado de que luego de 40 años Rocinante vuelva al camino jineteado por el mismo Quijano de las broncas y las anticipaciones" (ONETTI, 1979, p.3), para otros Quijano se había llevado Marcha al exilio porque no podía vivir sin ella. Y Marcha tampoco pareciera poder vivir sin Quijano por lo que en el número 27 titulado: Murió Carlos Quijano se afirmaba: "Marcha es una labor estrechamente vinculada a la vida de Carlos

consultarse los trabajos de: RONIGER (2015); RONIGER y YANKELEVICH (2009); YANKELEVICH (2009); YANKELEVICH y JENSEN (2007); GIARDINELLI y BERNETTI (2003) y DUTRÉNIT BIELOUS (2006).

${ }^{4}$ Entre ellos podemos destacar los trabajos de SARLO (1992); BEIGEL (2003); MORAÑA (2003); DOSSE (2007); PLUET DESPATIN (1992); SIRINELLI (1986); JULLIARD (1987). 
Quijano. Con el número 27 se cierra la segunda época de Cuadernos y se cierra también, una larga, fecunda y valiente tarea editorial” (CUADERNOS DE MARCHA, 1984, p. 3). Salieron tres números más que publicaron sus discursos rindiéndole homenaje a sus palabras: "Las voces del silencio, entre ellas la nuestra, volverán a hacerse oír. Con nosotros o sin nosotros" $" 5$. La icónica foto del barco con sus velas desplegadas y la frase "navigare necesse vivere non necesse" cobraba pleno sentido. ${ }^{6}$

Los primeros números fueron monográficos y se centraron en la situación de los países latinoamericanos frente a la dictadura (Uruguay, Argentina, Bolivia, Perú, Nicaragua, Chile), y después la revista ensayó otra línea de intervención, más parecida a la de Marcha, y mensual. Una variedad de temas y colaboradores encontraron espacio en la revista y nutrieron sus debates. Desde textos literarios y culturales hasta políticos y económicos, acompañando los primeros años de la década del ochenta y la denominada "transición democrática" de varios países latinoamericanos. Su Consejo editorial estaba integrado por: Samuel Lichtensztein (economista), Carlos Martínez Moreno (escritor, ensayista y abogado), Nelson Minello (sociólogo), José Manuel Quijano (economista), Raúl Trajtemberg (economista y Profesor), Guillermo Waksman (periodista y traductor), Rubén Svirsky (periodista), Teresa de Barbieri (socióloga especialista en temas de género) y Gustavo Melazzi (economista). Y colaboraron: Arturo Ardao (filósofo e historiador de las ideas), Juan Carlos Onetti (escritor), Angel Rama (escritor y ensayista), Héctor Borrat (periodista y docente universitario) Mario Benedetti (escritor) y Eduardo Galeano (escritor y periodista).

\footnotetext{
${ }^{5}$ Los Cuadernos volvieron a ser editados en Montevideo a partir de 1985 con el "regreso a la democracia", iniciándose así su tercera época. Si los primeros números fueron monográficos y se centraron en el pensamiento de Carlos Quijano y de Julio Castro, a partir del número 8 adquirieron el tono de los Cuadernos del exilio pero presentaban lo que se denominó un cambio generacional. La empresa editorial conservó la marca y la sangre Quijano, ya que fueron sus hijos José Manuel y Mercedes y su nieto Carlos Vargas Quijano los que continuaron la marcha pero muchos de los antiguos colaboradores de desvincularon de. Como toda empresa familiar y personal, con la muerte de Mercedes y Carlos en un accidente automovilístico, dejó de salir en 2001.

${ }^{6}$ En el volumen de Marcha del 13 de enero de 1967 se incorpora, sin ninguna aclaración, la imagen del barco junto con la inscripción: Navigare Necesse, Vivere Non Necesse (literalmente: Navegar es necesario, vivir no es necesario). En el ejemplar del 31 de marzo del mismo año se publica una carta lector preguntando ¿qué quiere decir esa inscripción que ponen junto al nombre de MARCHA?. A este lector, la redacción de Marcha le respondió:"Navegar es necesario, vivir no lo es, dijo Pompeyo, según Plutarco, a unos marinos que no querían hacerse a la mar mientras no amainara la tempestad. La frase fue, en su forma latina, la divisa de la 'Casa de Navegación' de Bremen desde su fundación a principios del siglo XVI. Podríamos haber puesto: marchar, militar es necesario, vivir no lo es" (PIÑEYRÚA, 2007, p.9) Años después diría Alfaro sobre esta frase: "No se trata de vivir, en el sentido de durar, o de gastar los días sin rumbo (...) sino de navegar, de abrir camino a lo nuevo, donde todo es cuestionado y todo nos cuestiona". (ALFARO, 1984, p. 24-25).
}

\section{GANPHLAC}

Revista Eletrônica da ANPHLAC, ISSN 1679-1061, No. 19, p. 186-207, jul./dez., 2015. 
En todos los números estuvo presente la que por años había sido la misión de Marcha, combinar la perspectiva nacional y latinoamericana para leer la realidad, como también el proyecto de Carlos Quijano de construir una conciencia latinoamericana. Esa conciencia latinoamericana era para su director una práctica intelectual y política que venía desplegando desde su juventud en Marcha y que tenía su antecedente en la creación en 1925 en Paris de AGELA (Asociación General de Estudiantes Latinoamericanos) en la que entabló vínculos con otros latinoamericanos como el peruano Víctor Raúl Haya de la Torre, el cubano Julio Antonio Mella, el mexicano Carlos Pellicer, el guatemalteco Miguel Ángel Asturias, el salvadoreño Toño Salazar y el nicaragüense León de Bayle ${ }^{7}$.

Convocados por Miguel Angel Piccato, de extracción radical, varios intelectuales argentinos exiliados en el Distrito Federal e identificados con el peronismo de izquierda y el socialismo se reunieron con la intención de crear una revista de denuncia de la situación Argentina. Puesto que varias revistas comenzaron a circular con esta pretensión, finalmente decidieron publicar una revista de debate y reflexión; y así nació Controversia para el examen de la realidad argentina. Esta revista publicó sus 14 números (en realidad fueron 13 número ya que por error o superstición el número 13 se salteó) entre octubre de 1979 y agosto de 1981 bajo la dirección de Jorge Tula (filósofo) y un consejo de redacción integrado por: Carlos Abalo (periodista), José Aricó (ensayista, editor), Sergio Bufano (escritor), Sergio Caletti (sociólogo y periodista), Nicolás Casullo (filósofo, escritor), Ricardo Nudelman (economista), Juan Carlos Portantiero (sociólogo y ensayista), Héctor Schmucler (sociólogo y semiólogo) y Oscar Terán (filósofo) ${ }^{8}$.

Entre los ejes que se discutieron en sus páginas pueden mencionarse: la derrota de la experiencia guerrillera y la crítica a Montoneros, la situación Argentina, y los problemas en torno a la construcción y el sentido de la democracia a partir de la crisis del marxismo, la

\footnotetext{
${ }^{7}$ Sobre Marcha y la primera época de los Cuadernos, véase: ALFARO (1984); ESPECHE (2010); MACHIN y MORAÑA (2003); PEIRANO BASSO (2001); PIÑEYRÚA (2007) y PINHEIRO DE PAULA COUTO (2012).

${ }^{8}$ La publicación fue el resultado de la convergencia de lo que conoció como la mesa peronista y la mesa socialista nucleadas en la Comisión Argentina de Solidaridad (CAS) en México. En 1979 surge la mesa peronista que contaba entre sus miembros con Jorge Bernetti, Luis Bruschstein, Sergio Caletti, Nicolás Casullo y Ernesto López. La mesa socialista estaba integrada por José Aricó, Sergio Bufano, María Candelari, Horacio Crespo, Emilio de Ípola, Néstor García Canclini, Ricardo Nudelman, Nora Rosenfeld, Osvaldo Pedroso, Juan Carlos Portantiero, Oscar Terán y Jorge Tula. Pero fueron las iniciativas de aquellos que habían participado de Pasado y Presente, como Juan Carlos Portantiero y José María Aricó, los que terminaron por conformar el grupo. Puede verse al respecto YANKELEVICH (2009).
}

\section{CANPHLAC}

Revista Eletrônica da ANPHLAC, ISSN 1679-1061, N. 19, p. 186-207, jul./dez., 2015. 
discusión de viejos aportes en una nueva coyuntura y las propuestas socialdemócratas ${ }^{9}$. Como su título lo indica Controversia estaba más destinada a reflexionar sobre la realidad argentina que la uruguaya Cuadernos de Marcha ${ }^{10}$. Y, a pesar del llamado a la controversia, las diferencias entre socialistas y peronistas dieron por terminado el proyecto editorial en 1981.

Si el exilio dio lugar al nacimiento de estas revistas, como posibilidad de enunciar y debatir, no es menos cierto que ciertas empresas editoriales previas y la pertenencia a algunas tradiciones político ideológicas legitimaron también la intervención de estos intelectuales. Toda revista es una obra colectiva que transforma la heterogeneidad de las individualidades en un piso mínimo compartido. Esta reducción de la multiplicidad a la unidad es un proceso que o bien puede vertebrarse a partir de una figura convocante como su director, o es el resultado de un derrotero genealógico que encuentra su unidad en un pasado común que puede ser el de un grupo, una empresa editorial, o un acontecimiento fundacional (SIRENELLI, 1986; PLUET-DESPATIN, 1992; JULLIARD, 1987).

Entre los linajes que saltan a la vista debe mencionarse para el caso de la revista uruguaya a Marcha y la primera época de los Cuadernos de Marcha ${ }^{11}$, y para el caso de la revista argentina, a Pasado y Presente ${ }^{12}$. Como linajes políticos puede mencionarse para ambas

\footnotetext{
${ }^{9}$ Sobre Controversia pueden consultarse los trabajos de BURGOS (2004); CHIOCCHETTI (2010); GAGO (2012); GAUNA (2014); PONZA (2010) y REANO (2012).

${ }^{10}$ Recién en el número 5 de marzo de 1980 aparece en Controversia una sección que lleva por título América Latina, y son pocas las notas escritas por colaboradores latinoamericanos que no sean argentinos. Se publica un ensayo de Angel Rama sobre Argentina, "Argentina: crisis de una cultura sistemática" en el número 8 de septiembre de 1980, un artículo de Fernando Henrique Cardoso en el número 7, "Las sorpresas del desarrollo en América Latina" y otro de Joaquín Brunner sobre "La izquierda chilena: identidad en la encrucijada".

${ }^{11}$ Marcha fue fundada por Quijano el 23 de junio de 1939 hasta su clausura por el gobierno cívico militar de Juan María Bordaberry el 22 de noviembre de 1974. Fue un semanario político y cultural destacado de Uruguay, tanto por su línea independiente como por el equipo de colaboradores. Entre estos estuvieron Julio Castro, Sarandy Cabrera, Arturo Ardao, Alfredo Mario Ferreiro, Hugo Alfaro, Homero Alsina Thevenet, Carlos Martínez Moreno, Manuel Flores Mora, Carlos Real de Azúa, Mario Benedetti, Pablo Mañé Garzón, Álvaro Castillo, Eduardo Galeano, Ángel Rama, Alfredo Zitarrosa, Rubén Enrique Romano, María Esther Gilio, Gerardo Fernández, Salvador Puig y Guillermo Chifflet. Los Cuadernos de Marcha, se publicaron mensualmente en Montevideo entre 1967 y 1974, y se caracterizaron por tratar en mayor profundidad temas monográficos que los diferenciaron de la revista.

${ }^{12}$ Pasado y Presente (1963-1965) fue una revista de orientación marxista publicada en Córdoba, que se centró en la renovación teórica y cultural del marxismo. Estuvo dirigida, en su primer año de vida, por Oscar del Barco y Aníbal Arcondo, sumándose a partir de su segundo año José María Aricó, Samuel Kieczkovsky, Juan Carlos Torre, Héctor Schmucler, César Guiñazú, Carlos Assadourian, Francisco Delich, Luis J. Prieto y Carlos R. Giordano. Los temas que caracterizaron esta primera época fueron: la crítica al partido comunista, la difusión del pensamiento de Gramsci y otros clásicos del marxismo, la publicación de numerosos artículos de intelectuales de izquierda contemporáneos -sobre todo italianos-, la discusión en torno a la lucha armada y el mundo obrero cordobés, la relación entre cultura y política. Una segunda época, bajo la dirección de José María Aricó apareció en 1973, dando cuenta del acercamiento de estos intelectuales a la izquierda peronista.
}

\section{GANPHLAC}

Revista Eletrônica da ANPHLAC, ISSN 1679-1061, No. 19, p. 186-207, jul./dez., 2015. http://revista.anphlac.org.br 
la izquierda, en el caso argentino identificada con el socialismo y el peronismo revolucionario y para el caso uruguayo con el Frente Amplio del que tanto Quijano como Moreno fueron artífices. Para ambas el advenimiento dictatorial y el exilio fue fundacional.

Es por ello que si bien el exilio fue un momento de quiebre importante para los intelectuales reunidos en estas publicaciones, fue también un punto de condensación o cristalización de cambios y transformaciones que se venían dando hace algunos años por lo que estas revistas resultan emblemáticas como bisagras entre las décadas del setenta y ochenta.

\section{México, el nombre del exilio}

El punto de partida tanto de los Cuadernos como de Controversia fue el exilio por lo que ambas pueden ser definidas como revistas del exilio. Pero en estas páginas buscamos desarrollar la idea que ese exilio no fue sólo una situación personal o profesional de sus miembros, con todo lo que ello implicaba, sino el aglutinante, el cimiento que se convirtió en diálogo fecundo y punto de reunión. Y México fue el destino en el que su estado democrático dio garantías a los exiliados, al paso que condenaba internacionalmente a las dictaduras. El hecho que en sus librerías se pudieran encontrar todo tipo de libros de izquierda y que al Distrito Federal llegaran publicaciones, ya sean clandestinas o no, y las producidas desde distintos exilios, daba cuenta de esta particularidad.

México se convirtió, de este modo, en un lugar de acogida sumamente importante. Los exiliados encontraron en este país condiciones socioculturales muy favorables que permitieron tanto que los contactos entre exiliados latinoamericanos fueran asiduos, como la convivencia y confrontación intelectual. Fueron varios los ámbitos que funcionaron como lugares de encuentro para los intelectuales argentinos y uruguayos. Los editores de Controversia se desempeñaron en periódicos (Sergio Bufano fue secretario de redacción de la sección latinoamericana de Le Monde Diplomatique), empleos en el gobierno (Sergio Bufano fue asesor de la Secretaría de Prensa de la Presidencia de México), editoriales (José Aricó y Jorge Tula trabajaron en Siglo XXI y Ricardo Nudelman en Editorial Folios), librerías (Ricardo Nudelman en Gandhi), y el mundo académico (Juan Carlos Portantiero se desempeñó en la Facultad Latinoamericana de Ciencias Sociales - FLACSO-, Nicolás Casullo y Carlos Ábalo en Universidad Nacional Autónoma de México -UNAM-, Héctor Schmucler y Sergio Caletti

\section{GANPHLAC}

Revista Eletrônica da ANPHLAC, ISSN 1679-1061, No. 19, p. 186-207, jul./dez., 2015. http://revista.anphlac.org.br 
en Universidad Autónoma Metropolitana -UAM) (véase GAUNA; 2014). Los miembros de los Cuadernos también compartieron estos espacios: Carlos Quijano impartía cursos en la Facultad de Ciencias Políticas de la UNAM y escribía en la revista Proceso y fundó en 1979 el Centro de Estudios Uruguay-América Latina (CEUAL), ámbito de investigación y análisis abierto a los exiliados uruguayos y a militantes y científicos sociales mexicanos en el Distrito Federal. Samuel Lichtensztejn fue director del Instituto de Estudios Económicos de América Latina del Centro de Investigación y Docencia Económicas (CIDE) y Carlos Martínez Moreno desempeñó también un cargo en la Facultad de Ciencias Políticas y Sociales de la UNAM. Esta convivencia fue facilitada por la extraordinaria expansión de las Universidades e institutos de investigación mexicanos (entre ellos la UNAM y de la Facultad Latinoamericana de Ciencias Sociales, FLACSO México) como resultado en lo económico del boom del petróleo, y en lo político del proceso de democratización iniciado con el gobierno de Luis Álvarez Echeverría (1970-1976) y continuado por José López Portillo (1976-1982).

En señal de gratitud a la hospitalidad mexicana puede explicarse que ninguna de las dos revistas haya tematizado su política. Según Varela Petito acerca de Cuadernos: "en lo concerniente a México, al ser dirigida por un extranjero, la publicación debía llamarse a reserva en lo político, por lo que las referencias eran sobre todo al ámbito cultural y ocasionalmente al análisis económico" (2008, p. 120).

Pero México no fue sólo experimentado por los exiliados como el lugar de la libertad y la democracia sino como el lugar desde donde descubrieron, de la mano del mestizaje, a lo latinoamericano. Si toda revista, al decir de Pluet-Despatin (1992) es un punto de encuentro de itinerarios personales, sin duda México y la condición de exiliados de los uruguayos y argentinos allí reunidos, fue central en la construcción de una impronta latinoamericana.

Es así que, como veremos, este exilio mexicano se convirtió en condición de posibilidad de estas revistas en el que se fue construyendo una particular idea de unidad. Unidad que suponía cohesión hacia adentro del cuerpo social identificado con la nación de pertenencia, en la que las diferencias entre tradiciones políticas y perspectivas ideológicas se desdibujaba, pero también cohesión hacia afuera, en la construcción de una comunidad de naciones latinoamericanas. Es así que tal como sostiene Roniger "ha sido en el extranjero que muchos de los desplazados han descubierto, re-descubierto o bien inventado el 'alma colectiva' de su

\section{CANPHLAC}

Revista Eletrônica da ANPHLAC, ISSN 1679-1061, N. 19, p. 186-207, jul./dez., 2015. 
nación en términos primordiales o espirituales" (2015, p. 12). Sin embargo, esta pertenencia latinoamericana no tendrá el mismo peso en las dos publicaciones.

En el primer número de la segunda época de los Cuadernos, titulado: Uruguay: Encierro, destierro o entierro, de mayo/junio de 1979, afirmaba Quijano en su nota "Los caminos de la liberación":

Junio tiene para nosotros connotaciones diversas: hace cuarenta años apareció Marcha; hace seis se instaló la dictadura en Uruguay. Ambos hechos se entrelazan y se excluyen. Marcha fue un áspero y anticipado combate contra lo que encarna la dictadura, contra todas las fuerzas que la engendraron. Quizá no lo supimos cabalmente; pero creemos haberlo intuido: ese combate era implacable y no admitía transacción ni tregua. El honor de Marcha fue el de haber asumido ese su modesto cometido. Si lo hizo mal o bien, no corresponde a nosotros decirlo. Lo cierto es que para vivir se negó a perder su razón de vivir. Fue perseguida y acallada; pero el fin aún no ha llegado. Ahora en México, que nos dio trabajo y paz, reiniciamos la publicación de los Cuadernos para servir a nuestro pago y a nuestra América. Todos los que escriben en este número viven en el exilio, como tantos y tantos cientos de orientales desparramados por el mundo. Muchos, la mayoría, fueron además colaboradores de Marcha. Ninguno de los convocados desoyó el llamado. A la hora del rencuentro sólo faltaron aquellos que están presos o fueron asesinados como Zelmar Michelini o murieron en la tortura como Julio Castro. Ellos, los ausentes, sin embargo, siempre estarán presentes. No acudieron a la cita; pero seguirán haciendo con nosotros el camino que hoy se reabre (QUIJANO, 1979a, p. 3).

En esta definición programática de los Cuadernos, no sólo se explicitaba la continuidad de esta revista con el proyecto de Marcha, sino también sus intenciones de intercomunicar el exilio, comunicar al exilio con el Uruguay y al Uruguay con América Latina. Es así que Quijano entabló lazos con los uruguayos del exilio, especialmente los que se radicaron en México a través del Comité de Solidaridad con Uruguayos (COSUR), con otros en Europa (desde Suecia a España); como también con otros exiliados latinoamericanos e intelectuales mexicanos ${ }^{13}$.

Para Galeano, exiliado en Barcelona:

El exilio, que siempre nace de una derrota, no solamente proporciona experiencias dolorosas. Cierra unas puertas pero abre otras. Es una penitencia y, a la vez, una libertad y una responsabilidad. Tiene una cara negra y tiene una cara roja. (...) El exilio desarrolló este intercambio en un grado improbable en situaciones "normales", cuando lo "normal" en América Latina es la ignorancia recíproca de sus partes (GALEANO, 1979, p. 86).

\footnotetext{
${ }^{13}$ Las cartas de lectores ocupan un lugar importante en los Cuadernos y denotan el interés de los uruguayos exiliados en todo el mundo por la publicación. Fundamentalmente aquellos militantes políticos vinculados al Partido Socialista y al Frente Amplio, del que Quijano había sido un importante artífice.
}

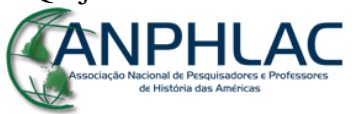

Revista Eletrônica da ANPHLAC, ISSN 1679-1061, No. 19, p. 186-207, jul./dez., 2015. http://revista.anphlac.org.br 
El exilio aparece como generador de una excepcionalidad: el encuentro de los latinoamericanos. Situación que aparece caracterizada como improbable o no normal, lo que da cuenta de la importancia que tiene, para estos intelectuales, como momento fundante de un nuevo colectivo transnacional. Para Ángel Rama:

Ya se ha dicho varias veces que los militares conservadores han fortalecido la compenetración de la intelectualidad del continente, que han ayudado a su mejor formación y ampliación de conocimientos, aunque esto venía ocurriendo desde hace bastantes décadas, sólo que se aplicaba a los "otros" del continente y, no a los "sureños", como se había aplicado a los españoles transterrados a Hispanoamérica y ahora a los hispanoamericanos que han buscado cobijo en una España que por razones obvias no puede sino recibirlos a pesar de sus presentes dificultades (RAMA, 1979, p. 79).

En el mismo momento en que la tiranía acantona a la población uruguaya dentro de las fronteras bloqueadas, sumiéndola en el provincialismo y en la ignorancia del vasto mundo, más intercomunicado que nunca, el pueblo de la diáspora y sus intelectuales están participando en un activo intercambio, haciendo suyos los problemas de otras comunidades, viviendo sus afanes, conociendo su historia, apropiándose de su legado histórico, sirviendo a estas culturas de adopción como lo hicieron con la suya propia y aportando dentro de ellas. Si para muchos uruguayos conocer la América indígena o la América negra ha sido una revelación que sin duda los favorecerá porque les proporciona un entendimiento más cabal de la pluralidad americana al tiempo que les hace copartícipes de ricas tradiciones intelectuales y artísticas, también ha sido grande la contribución que sus sistemas de referencias y sus percepciones culturales han hecho a las respectivas zonas en las que se han instalado (RAMA, 1979, p. 80).

A este activo intercambio, asumido como algo poco común, se sumaba el hecho de que el quiebre de la democracia en Uruguay rompía con su excepcionalidad: con el mito de la Suiza de América, de la Atenas del Plata, el País modelo y el slogan "como el Uruguay no hay", para ponerla en diálogo con otras naciones que también tenían sus sistemas políticos en manos de los militares. En otras palabras, se reactivaba otro mito de unidad pero que excedía las fronteras nacionales, el de la unidad latinoamericana.

Es así que frente a un problema común: el de las dictaduras militares y la persecución política e ideológica, Quijano se preguntaba: "La represión se ha internalizado, repetimos ¿puede la lucha contra ella encerrarse en el ámbito nacional? ¿no escapa a las fronteras?" (1980b, p. 4).

En esta construcción colectiva, el exilio se presentaba con cierta positividad. Ya lo apuntamos para el caso Uruguayo con Rama y Galeano y es puesto en estas palabras en la primera editorial de Controversia:

\section{GANPHLAC}

Revista Eletrônica da ANPHLAC, ISSN 1679-1061, No. 19, p. 186-207, jul./dez., 2015.

http://revista.anphlac.org.br 
Han pasado más de tres años desde que se produjera el golpe militar en la Argentina. Al estupor por la salvaje represión, al anonadamiento producido por el forzado alejamiento de la patria, al desconcierto inicial respecto de la dirección y efectividad de nuestros actos, hoy, o desde no hace mucho tiempo, (aunque siempre nos resistimos a la negatividad del exilio, enfrentando con variado éxito a "la melancolía, la frustración y la nostalgia”) existe la convicción cada vez más firme de convertir este exilio "en una experiencia positiva". (CONTROVERSIA, 1979, p. 2).

Si el exilio propiciaba la unidad y el encuentro, esta situación también era estimulada en las revistas. Al decir de Galeano, Cuadernos fue plural y abierta desde un primer momento como símbolo de su democratismo, destacando, casi como un reproche, la capacidad de Quijano para convocar personalidades de distintas preferencias políticas y hacer que las páginas de la revista estuvieran abiertas a reflexiones de todo el espectro político (GALEANO, 1981, p. 51) ${ }^{14}$. Y en Controversia se enunciaba como definición identitaria.

Si muchos habían sido educados en "una izquierda dogmática" o en el movimiento popular "en cuyas estructuras reinaba el autoritarismo" ahora la misión era otra. "Es difícil, lo repetimos. Pero es posible. Es posible iniciar una controversia lúcida, serena, fraternal. Es posible, y necesario, respetar al compañero. Si así no lo fuera, el tiempo habrá pasado en vano" (CONTROVERSIA, 1979, p. 2).Controversia llamaba a quebrar con una tradición muy arraigada en la cultura política argentina en la que la ideología funcionaba como un parteaguas que dicotomizaba el espacio político entre amigos y enemigos; una práctica que la revista se proponía revertir.

No obstante, no siempre la controversia se desplegó en sus páginas. La nota de Héctor Schmucler “Testimonio de los sobrevivientes" (SCHMUCLER, 1980b) generó todo tipo de comentarios y una réplica por parte de Mempo Giardinelli que a pesar de haber sido pensada para Controversia no fue publicada por esta revista sino por los Cuadernos. Giardinelli explicaba lo ocurrido de este modo: "Originariamente esta nota fue presentada a la revista Controversia, pero los editores de dicha publicación no quisieron incluirla en sus páginas. Por esa razón, me considero en libertad de ofrecérsela a ustedes”. (GIARDINELLI, 1981, p. 98). La revista Cuadernos estaba acostumbrada a publicar notas de argentinos. Menos centrada en el país de pertenencia de sus miembros (de ello dieron cuenta sus primeros números), en sus páginas convivían sin dificultad los peronistas Mempo Giardinelli y de José Luis Bernetti junto a los socialistas Oscar Terán o Juan Carlos Portantiero.

\footnotetext{
${ }^{14}$ En la nota se refiere al eclecticismo de Quijano y a Marcha como lección de pluralidad democrática. 
Pero, a pesar de estas diferencias, ambas revistas se identificaron con la izquierda y sus proyectos de transformación social y, a partir del exilio, ensayaron un camino de autocrítica que descansaba en un diagnóstico común con respecto al pasado reciente: el de la derrota de los proyectos revolucionarios y el de los errores cometidos.

\begin{abstract}
Muchos de nosotros pensamos, y lo decimos, que sufrimos una derrota atroz. Derrota que no sólo es la consecuencia de la superioridad del enemigo sino de nuestra incapacidad para valorarlo, de la sobrevalorización de nuestras fuerzas, de nuestra manera de entender el país, de nuestra concepción de la política. (CONTROVERSIA, 1979 , p. 2)
\end{abstract}

Reconozcámoslo. Hemos cometido muchos errores. Hemos construido muchas utopías vanas. Hemos dilapidado muchas reservas que nos habían sido confiadas. Hemos hecho uso y abuso de triunfalismo retórico y de ideologías rancias. Consignas y esquemas nos han eximido de reflexionar. Ahí está nuestra triste América del Sur, que perdimos y a la que no hemos sido capaces de reconquistar (QUIJANO, 1980b, p.4).

Ambas revistas reconocían que la derrota no había sido sólo militar sino de ciertas matrices teóricas para interpretar la realidad, en otras palabras, que ciertas ideas que sostuvieron en el pasado habían sido derrotadas y debían ser revisadas. En Controversia ese reconocimiento de la derrota política e ideológica en manos del Proceso era más que un punto de partida, era el sustrato que permitía la unidad de sus corrientes internas, es decir tanto de los socialistas como de los peronistas revolucionarios que habían apoyado de diversas formas a las organizaciones armadas. Más allá de que la derrota fuese cuestionada y sometida a arduos debates, y que para Schmucler "todos derrotados pero no con la misma responsabilidad" refiriéndose al peronismo y a la guerrilla (SCHMUCLER, 1980a, p. 4), era el cimiento compartido entre ambas tradiciones que hacían de la autocrítica y la revisión de lo que fueron las estrategias pasadas otro de sus puntos de encuentro.

Para los Cuadernos la idea de la derrota aparecía asociada a los errores del pasado y como punto de partida para pensar lo nuevo; la derrota no era sólo una derrota individual o de los proyectos de izquierda sino la de una región. Es por ello que la derrota no era tanto un momento de encuentro en un pasado compartido sino que, articulada a la idea del exilio, era un punto de encuentro para un futuro a compartir. El encadenamiento argumental se presentaba del siguiente modo: la derrota había conducido al exilio, y ese exilio aparecía como condición de posibilidad para vertebrar un nuevo proyecto. En palabras de Quijano: “Un día la diáspora latinoamericana cesará. Otras patrias y otra patria habrá que crear. Si somos capaces de

\title{
GANPHLAC
}

Revista Eletrônica da ANPHLAC, ISSN 1679-1061, №. 19, p. 186-207, jul./dez., 2015.

http://revista.anphlac.org.br 
contribuir a que esta esperanza vital se mantenga, y llegado el día, cuaje, la travesía, ahora reemprendida estará justificada" (1980a: contratapa).

El exilio cobraba sentido para Quijano si era parte de una gesta emancipadora en la que Uruguay se montaba en un compendio de naciones. Ardao, refiriéndose a Quijano supo decir que el suyo era "un latinoamericanismo de fundamento ante todo económico y de sentido social esencialmente antiimperialista y anticapitalista, bandera de una patria continental erigida sobre el conjunto de las patrias chicas" (ARDAO, 2003, p. 174).Y era a partir de ese latinoamericanismo que la unidad era posible.

\section{América Latina, Democracia y Socialismo}

Con respecto al futuro político y a la democracia, el tono de los Cuadernos osciló entre la crítica y la esperanza sobre lo que avizoraban como un futuro incierto. Su director planteaba que no se trataba "de restablecer la democracia, sino de reconstruirla. Sin duda el "restablecimiento de la democracia" tiene prioridad. Pero ¿de qué democracia se trata? O, si se prefiere, ¿de qué instituciones democráticas se trata?”(QUIJANO, 1979a, p. 3). La democracia en tanto concepto era sometido a la reflexión. No se planteaba una vuelta al pasado democrático previo al golpe sino que el corte que había significado la dictadura militar aparecía en sus argumentos como un quiebre a partir del cual era necesario repensar y (re)construir las instituciones democráticas.

El camino a transitar se planteaba como uno común a varios países latinoamericanos, a otras patrias en palabras del director. Y ese punto de llegada, que asumía el nombre de democracia, no estaba prefijado de antemano y se encontraba sujeto a la construcción política. Nuevamente en palabras de Quijano: "Democracia, integración, ruptura del modelo capitalista, de ahí, según pensamos y creemos con angustia y esperanza las metas de nuestro difícil y extenuante quehacer. Otra América vendrá, ¿cuál? La que seamos capaces de construir" (QUIJANO, 1979a, p. 13).

Si bien la reflexión en torno a la democracia como invención y lugar de incertidumbres no es nueva, resulta interesante notar que la imagen de incertidumbre e inseguridad que provoca el exilio es capitalizado de un modo positivo para pensar la democracia. El fin de las certezas y las ideas rectoras de los años setenta, el fracaso de los

\section{GANPHLAC}

Revista Eletrônica da ANPHLAC, ISSN 1679-1061, No. 19, p. 186-207, jul./dez., 2015. 
proyectos político ideológicos con los que se habían identificado estos intelectuales, y la revisión de su accionar en el pasado reciente teñido de autocrítica, fue el telón de fondo para pensar una democracia plural y de alcances regionales.

La idea de que era necesaria la unidad de las fuerzas políticas y sociales de cada país, junto a la unión entre naciones hermanas estaba tan presente en Quijano que a través de los Cuadernos buscó unir lo que él llamaba la patria chica (su Uruguay) con la patria grande (Latinoamérica); unir al ser nacional con el ser latinoamericano ya que Uruguay no estaba sola "de ahí la necesidad de las integraciones, que las partes se unan y forman el todo" (QUIJANO, 1983, p. 7). Y en este camino, "si nuestra América es un todo o pretendemos que lo sea, ninguno de sus miembros puede estar enfermo."(QUIJANO, 1979b, p. 4). ${ }^{15}$ Afirmación que llevaba inevitablemente a colaborar al restablecimiento democrático en otras patrias y a reflexionar sobre ello.

Quijano articulaba un punto de partida común, con un punto de llegada también común: "a todos los países los une, por encima de fronteras, una finalidad común; pero de la que aún no existe conciencia clara y que no constituye un firme aglutinante" (QUIJANO, 1980c, p. 3). En un intento por construir un futuro democrático que se presentaba como incierto y sujeto a la contingencia, el mismo era montado sobre una esencia común, que aglutinaba las experiencias de los países latinoamericanos. Esa esencia funcionaba como un a priori necesario para la democracia pero que aparecía como desconocido e incierto. Si la democracia no estaba prefijada de antemano ni descansaba en un pasado al que debía volverse, aparecía articulada, en el argumento de Quijano, a una esencia común: la unidad latinoamericana.

Para Arturo Ardao, cuyas notas filosóficas junto a los editoriales de Quijano fueron delineando el proyecto de la revista, era posible articular lo nacional a lo universal porque "el latinoamericanismo es en definitiva un nacionalismo, en cuánto expresión de una verdadera conciencia nacional" (ARDAO, 1983, p. 11-12). Y ese era un nacionalismo compatible con la democracia, con la identidad latinoamericana y la integración regional que Quijano buscó construir. Es así que en su perspectiva la realización de la democracia latinoamericana estaba sujeta al descubrimiento/invención de esa conciencia nacional. Y su descubrimiento estaba atado al conocimiento de las problemáticas latinoamericanas y no sólo del Uruguay.

\footnotetext{
${ }^{15}$ La nota se refiere a Argentina y suscitó críticas y elogios por parte de los argentinos. Entre los primeros Rodolfo Puigróss y entre los segundos Rodolfo Terragno.
}

\section{GANPHLAC}

Revista Eletrônica da ANPHLAC, ISSN 1679-1061, N. 19, p. 186-207, jul./dez., 2015. 
Mientras el socialismo a la Quijano era un socialismo no dogmático, no ortodoxo, un socialismo a la uruguaya que se apoyaba en Marx (CUADERNOS DE MARCHA, 1985, p. 3), y por eso era compatible con la democracia y el nacionalismo; en Controversiala definición del socialismo asumía otras complejidades.

El problema de la democracia y su relación con el socialismo empapa las páginas de Controversia. Desde una arista teórica en la que varios intelectuales participan del debate reflexionando acerca de las posibilidades del socialismo, desde otra arista latinoamericana vinculada al accionar de la Internacional Socialista y que reflexionaba sobre la crisis del marxismo, y una última arista nacional, en la que se contraponen socialistas y peronistas en sus definiciones de la democracia y lo nacional, haciendo especial hincapié en el pasado reciente. En esta última nos centraremos.

Los miembros de Controversia coincidían en la autocrítica por el desprecio que la democracia había despertado en el pasado reciente y en la necesidad actual de nuevos acuerdos. No obstante, en un tributo a la "controversia", el interés por el ideal democrático reactivaba la oposición entre diferentes adjetivaciones democráticas (democracia social, sustantiva, real vs. democracia formal, institucional) que llevaba a uno de los miembros del ala peronista a preguntarse “¿Podría afirmarse que todos los que estamos hoy por la democracia compartiremos mañana las mismas trincheras?" (CALETTI, 1980, p. 27). Si frente a la dictadura que había perseguido por igual a aquellos identificados con la tendencia revolucionaria, era posible pensar en común un futuro para la Argentina, frente al recambio militar y a la creación de la Multipartidaria, la pregunta de Caletti aparecía como todo un desafío.

Héctor Schmucler, en el anteúltimo número de la publicación, se preguntaba por las posibilidades de desdibujar estas diferencias:

\footnotetext{
¿Qué significa hablar de socialismo o peronismo si se pudiera acordar, a priori, en un modelo de sociedad para la existencia de los hombres concretos?

¿Por qué aferrarse a esquemas anacrónicos y no pensar todo de nuevo para inventar (o reinventar) el movimiento que aglutine a las fuerzas que en la sociedad argentina aspiran a un cambio en el sentido descrito? (SCHMUCLER, 1981, p. 15).
}

Schmucler aludía a la posibilidad lefortiana de inventar o reinventar un movimiento capaz de generar unidad, que reconociendo las diferencias pudiese acordar en un a priori, como cimiento para establecer el diálogo. Más allá de los cuestionamientos a un a priori común, Schmucler ponía en palabras la pretensión de construir un movimiento que aglutinara a

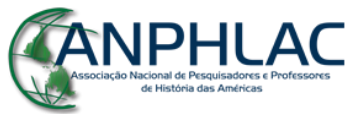

Revista Eletrônica da ANPHLAC, ISSN 1679-1061, No. 19, p. 186-207, jul./dez., 2015. http://revista.anphlac.org.br 
peronistas y socialistas. Un fundamento que, sin caer en esencialismos o en verdades últimas y reveladas, pudiera construir unidad.

Sin embargo, en el número siguiente, el último, Juan Carlos Portantiero y Emilio de Ípola parecían sellar el divorcio al afirmar como tesis que "no hay continuidad sino ruptura entre populismo (una de sus expresiones es el peronismo) y socialismo" (PORTANTIERO y DE ÍPOLA,1981, p. 11). Y desde la vereda peronista Casullo y Caletti, argumentaban en contra del socialismo que se desplegaba en las páginas de la revista:

\begin{abstract}
El primer aspecto que llama la atención en este sentido es que el nuevo discurso socialista no emerge de un análisis sobre la presencia del llamado socialismo y sus variantes en nuestro reciente pasado nacional (...) Cada una de sus versiones, cada una de sus nuevas teorizaciones nacieron y buscaron instalarse en el escenario político nacional a partir del impacto producido por las ideas que otras realidades generaban: adaptaciones y traslaciones, antes que elaboraciones de interrogantes y respuestas nacidos desde nuestra propia encrucijada nacional. (CASULLO y CALETTI, 1981, p. 9).
\end{abstract}

Lo nacional, que había sido desterrado por los socialistas como concepto legitimador de la acción política, se presentaba en el argumento de los peronistas como central. Y todo el artículo desplegaba una crítica en un registro que oponía posiciones nacionalistas a teorías extranjerizantes, y enfrentaba, una vez más, a peronistas y socialistas haciendo insalvables estas diferencias y llevando a Controversia a cerrar su empresa cultural.

\title{
Palabras finales
}

En estas páginas buscamos, a partir de Controversia y Cuadernos revisitar el exilio como lugar de sociabilidad, como terreno de denuncia, lugar en el que se reconfiguraron identidades políticas, se descubrió lo latinoamericano, se inició un camino de autocrítica y revisión del pasado reciente, y se imaginaron futuros democráticos. Y todo ello fue posible porque el exilio funcionó como topos de unidad.

Mientras en los Cuadernos la unidad que generaba cohesión en ese colectivo heterogéneo estaba articulada en torno a la figura de Quijano, y así lo afirmaron después de su muerte, en Controversia la unidad hacia adentro de la publicación, la otorgó la dictadura militar y su diferenciación con la organización Montoneros. En los primeros años de la revista Controversia el "otro" fue tanto el exilio armado como el Proceso, que funcionaron como

\section{GANPHLAC}

Revista Eletrônica da ANPHLAC, ISSN 1679-1061, No. 19, p. 186-207, jul./dez., 2015. 
alteridad que permitió el diálogo, y la democracia, en tanto horizonte futuro, aglutinó un "nosotros" entre tendencias político-culturales que cada vez tendían a diferenciarse más hasta que el recambio militar en 1981 y la presión de los partidos políticos agrupados en la Multipartidaria por iniciar un diálogo de apertura democrática, terminó por desarticular la precaria unidad.

También es posible afirmar que si en el caso de la revista uruguaya la unidad fue pensada hacia afuera, como unidad latinoamericana que permitía conectar y comunicar al Uruguay con otros países de América Latina, y en esa clave se pensó también la democracia y la izquierda antiimperialista, en el caso de la publicación argentina la unidad que se construyó era más bien una unidad hacia adentro de las fronteras nacionales entre tradiciones que si bien se reconocían enroladas en la izquierda mantenían sus diferencias. Nos referimos a los socialistas y peronistas.

Si bien estas expresiones de unidad no eran del todo nuevas, el latinoamericanismo estaba presente entre las preocupaciones de Quijano desde su juventud, y el llamado a la unidad nacional era parte constitutiva de la tradición peronista y en la izquierda revolucionaria había logrado cobijar a varias tradiciones políticas, lo cierto es que el descubrimiento de lo latinoamericano para el colectivo intelectual que representó los Cuadernos recibió nuevos bríos en el exilio y ese mismo exilio hizo posible que Controversia se convirtiera en el intento más serio de articular intelectualmente las tradiciones socialista y peronista. Ambas elaboraciones intelectuales estuvieron íntimamente vinculadas al pasado político y cultural de cada uno de estos países, y a la tradición más conciliadora, moderada y liberal, o belicosa, antagónica y populista, que se desplegó en cada orilla.

La unidad generada por el Frente Amplio en Uruguay a partir de su creación en 1971 fue importante a la hora de pensar una coalición de partidos (en el Frente convivían el partido comunista, el partido socialista, el partido demócrata cristiano y la coalición Izquierda Democrática Independiente), al punto que todos los grupos de izquierda que sobrevivieron a la dictadura consideraron que el Frente Amplio era la coalición imprescindible para el avance de los planteos programáticos de la izquierda (DE SIERRA, 1985). Visión de unidad a la que se sumaba que el plebiscito de 1980, con la derrota del sector militar, dio una imagen de unanimidad del cuerpo político bien aceptada por todos los sectores opositores al régimen. En el caso de los argentinos, no sólo los momentos de coaliciones o unidad fueron efímeros,

\section{GANPHLAC}

Revista Eletrônica da ANPHLAC, ISSN 1679-1061, N. 19, p. 186-207, jul./dez., 2015. 
fallidos o casi inexistentes, ya que la política argentina se caracterizó por la exclusión de los adversarios, al decir de Tulio Halperin Donghi (1994), sino que la propia experiencia de la Tendencia Revolucionaria, que había cobijado a peronistas y socialistas, desde un primer momento estuvo fracturada por sus corrientes internas condicionando su devenir después de la muerte de Perón.

Recapitulando un poco lo expuesto creemos que el exilio hizo posible que cada revista construyera una imagen de unidad, más frágil o más duradera, hacia adentro del espacio nacional o hacia afuera y que se correspondía con las particularidades de cada cultura política e ideológica. Intuimos que esa imagen devenida "mito", en la medida que vehiculizó solidaridades y se construyó de un modo simbólico e ideológico, posibilitó una construcción político-cultural característica que signó el derrotero de las democracias en Argentina y Uruguay.

\section{Referencias bibliográficas:}

ALFARO, Hugo. Navegar es necesario. Quijano y el Semanario Marcha. Uruguay: Editorial de la Banda Oriental, 1984.

ARDAO, Arturo. Uruguay y el nombre América Latina. Cuadernos de Marcha, México, número 1, mayo-junio, 1979.

. Nacionalidad y Continentalidad en América Latina. Cuadernos de Marcha, México, número 12, marzo- abril, p.7-14, 1981.

. El latinoamericanismo filosófico de ayer y hoy. Cuadernos de Marcha, México, número 19, mayo-junio, p.3-11, 1982.

Panamericanismo y Latinoamericanismo. Cuadernos de Marcha, México, número 23, septiembre, p. 3-12, 1983.

. La idea de latinidad y la idea latina. Cuadernos de Marcha, México, número 27, julio, p.13-20, 1984.

El latinoamericanismo de Quijano. In: MACHIN H. y MORAÑAM. (comps.) Marcha y América Latina.Estados Unidos: Pittsburgh University, 2003, p. 167-184.

BEIGEL, Fernanda. Las revistas culturales como documentos de la historia latinoamericana. Revista Utopía y Praxis latinoamericana, Venezuela, año 8, número 20, marzo p. 105-115, 2003.

\section{GANPHLAC}

Revista Eletrônica da ANPHLAC, ISSN 1679-1061, No. 19, p. 186-207, jul./dez., 2015. 
BERNETTI, Jorge Luis; GIARDINELLI, Mempo. México: el exilio que hemos vivido. Memoria del exilio argentino en México durante la dictadura 1976-1983. Bernal: Universidad Nacional de Quilmes, 2003.

BURGOS, Raúl. Los Gramscianos argentinos. Cultura y política en la experiencia de Pasado y Presente.Buenos Aires: Siglo XXI, 2004.

CALETTI, Rubén Sergio. Una historia sin resolver. Controversia para el examen de la realidad argentina, México, número 9-10, diciembre, p. 27-28, 1980.

CASULLO Nicolás; CALETTI Rubén Sergio. El Socialismo que cayó del cielo. Controversia para el examen de la realidad argentina, México, número 14, agosto, 1981, p.7-10.

CHIOCCHETTI, Magali. Exilio, memoria e identidades políticas. La revista Controversia. Para el examen de la realidad argentina y la revalorización democrática. Question, [S.1.], v. 1, n. 27 , sep. 2010. Disponible en: <http://perio.unlp.edu.ar/ojs/index.php/question/article/view/992>.

COUTO, Cristiano Pinheiro de Paula. El exilio entre la nostalgia y la creación. Revistas político-culturais latino-americanas e exílio (1978-1985). Revista Latino-Americana de História, vol. 1, número 4, dezembro de 2012.

CUADERNOS DE MARCHA. Editorial. Cuadernos de Marcha, México, número 27, julio, 1984, p. 3.

CUADERNOS DE MARCHA. Prólogo. Cuadernos de Marcha, México, número 34/35, julioagosto, s/n, 1985.

CONTROVERSIA. Editorial, Controversia para el examen de la realidad argentina, México, número 1, octubre, 1979, p. 2.

DE SIERRA, Gerónimo. La izquierda en la transición. Revista Mexicana de Sociología, México, vol. 47, número 2, abril-junio, 1985, p.111-121.

DOSSE, François. La marcha de las ideas. Historia de los intelectuales, historia intelectual.España: Universitat de Valencia, 2007.

DUTRÉNIT BIELOUS, Silvia. El Uruguay del exilio. Montevideo: Trilce, 2006.

ESPECHE, Ximena. Marcha del Uruguay: hacia América Latina. In: ALTAMIRANO, C. Historia de los intelectuales en América Latina II. Los avatares de la "ciudad letrada" en el siglo XX. Buenos Aires: Editorial Katz, 2010.

GAGO, Verónica. Controversia: una lengua del exilio. Buenos Aires: Publicaciones de la Biblioteca Nacional, 2012.

\section{GANPHLAC}

Revista Eletrônica da ANPHLAC, ISSN 1679-1061, No. 19, p. 186-207, jul./dez., 2015.

http://revista.anphlac.org.br 
GALEANO, Eduardo. El exilio, entre la nostalgia y la creación. Cuadernos de Marcha, México, segunda época, año 1, número 1, mayo/junio, 1979.

.Atados al mástil. Cuadernos de Marcha, México, número 12, marzo-abril, 1981.

GAUNA, Juan Pablo; Los cruces entre cultura y política en la edición de la revista: Controversia (En línea). Trabajo presentado en II Jornadas de Trabajo sobre Exilios Políticos del Cono Sur en el siglo $X X, 5,6$ y 7 de noviembre de 2014, Montevideo, Uruguay. Disponible en: http://www.memoria.fahce.unlp.edu.ar/trab_eventos/ev.3979/ev.3979.pdf

GIARDINELLI, Mempo. Los sobrevivientes de los testimonios. Cuadernos de Marcha, segunda época, México, número 11, enero-febrero,1981, p. 98-102.

HALPERIN DONGHI, Tulio. La larga agonía de la Argentina peronista. Buenos Aires: Ariel, 1994.

JULLIARD, Jacques. Le monde de revues au début du siècle. Mil neuf cent, 1987, p.3-9.

LEFORT, Claude.La invención democrática. Buenos Aires: Nueva Visión, 1990.

MACHIN, Horacio; MORAÑA, Mabel (Eds.). Marcha y América Latina. Pittsburgh: Instituto Internacional de Literatura Iberoamericana / Universidad de Pittsburgh, 2003.

MORAÑA, Mabel. Las revistas culturales y la mediación letrada en América Latina. Ilha de Santa Catarina, Brasil, 2 semestre, 2003, p. 67-73.

ONETTI, Juan Carlos. La piedra en el charco.Cuadernos de Marcha, segunda época, México, número 1, mayo-junio, 1979.

PEIRANO BASSO, Luisa. Marcha de Montevideo y la formación de la conciencia latinoamericana a través de sus cuadernos. Buenos Aires: Javier Bergara Editores, 2001.

PIÑEYRÚA, Pilar. Las tapas y titulares del Semanario Marcha una puerta grande a la argumentación, 2007. Disponible en: http://bdigital.uncu.edu.ar/2768. Acceso en: 27/04/15.

PINO, Miriam. El Semanario Marcha de Uruguay: Una genealogía de la crítica de la cultura en América Latina. Revista de Crítica Literaria Latinoamericana, Lima, segundo semestre, 2002, p.141-156.

PLUET-DESPATIN, Jacqueline. Une contribution a l'histoire des intellectuels: les revues. Cahiers de l'institut d histoire, Paris, número 20, marzo, 1992, p. 125-136.

PONZA, Pablo. La izquierda en su laberinto: intelectuales argentinos, ideas y publicaciones en el exilio (1976-1983). Boletín americanista [en línea], 2010,, Núm. 60, p. 247-262. http://www.raco.cat/index.php/BoletinAmericanista/article/view/194367

\section{GANPHLAC}

Revista Eletrônica da ANPHLAC, ISSN 1679-1061, No. 19, p. 186-207, jul./dez., 2015. 
PORTANTIERO, Juan Calos; DE ÍPOLA, Emilio. Lo nacional popular y los populismos realmente existentes. Controversia para el examen de la realidad argentina, México, número 14, agosto, 1981, p. 11-14.

QUIJANO, Carlos. Los caminos de la liberación. Cuadernos de Marcha, segunda época, México, mayo-junio de 1979a.

Declinación y estancamiento. Cuadernos de Marcha, segunda época, México, número 2, julio-agosto, $1979 \mathrm{~b}$. 1980a.

Contratapa. Cuadernos de Marcha, segunda época, México, número 5, enero-febrero,

Preguntas a las cabezas en reposo. Cuadernos de Marcha, segunda época, México, número 8 , julio agosto, $1980 \mathrm{~b}$.

Autocrítica y reafirmación. Cuadernos de Marcha, segunda época, México, número 6, marzo-abril, 1980c.

Reflexiones sobre Uruguay. Cuadernos de Marcha, número 22, julio, 1983, p. 3-7.

RAMA, Ángel. Otra vez la utopía en el invierno de nuestro desconsuelo. Cuadernos de Marcha, segunda época, México, número 1, mayo-junio, 1979.

REANO, Ariana. Controversia y La Ciudad Futura: democracia y socialismo en debate. Revista Mexicana de Sociología, Año 74, núm. 3, julio-septiembre, México, UNAM-Instituto de Investigaciones Sociales, 2012, p. 487-511.

REY TRISTÁN, Eduardo (comp.). Memorias de la violencia en Uruguay y Argentina. Golpes, dictaduras y exilios (1973-2006). Santiago de Compostela: Universidad de Santiago de Compostela, 2000.

RONIGER, Luis; YANKELEVICH Pablo. Exilio y política en América Latina: nuevos estudios y avances teóricos. EIAL, volumen 20, número 1, 2009.

RONIGER, Luis. Destierro y exilio en América Latina: un campo de estudio transnacional e histórico en expansión. Pacarina del Sur. año 6, núm. 23, abril-junio, México, 2015. Disponible en: http://www.pacarinadelsur.com/home/abordajes-y-contiendas/318-destierro-y-exilio-enamerica-latina-un-campo-de-estudio-transnacional-e-historico-en-expansion. Acceso en 15/07/2015.

SARLO, Beatriz. Intelectuales y Revistas: razones de una práctica. América, Cahiers du CRICCAL, Centre de la Sorbonne Nouvelle, Paris III, 1992, p. 9-15.

SCHMUCLER, Héctor. La argentina de adentro y la Argentina de afuera. Controversia para el examen de la realidad argentina, México, número 4, febrero, 1980a, p. 2-5.

\section{GANPHLAC}

Revista Eletrônica da ANPHLAC, ISSN 1679-1061, No. 19, p. 186-207, jul./dez., 2015.

http://revista.anphlac.org.br 
Testimonio de los sobrevivientes, Controversia para el examen de la realidad argentina, México, número 9-10, diciembre, 1980b, p. 4-5.

. Apuntes e interrogantes para reflexionar sobre política. Controversia para el examen de la realidad argentina, México, número 11-12, abril, 1981, p. 15.

SIRINELLI, Jean François.Le hasard ou la nécessité ? Une histoire en chantier: L'histoire des intellectuels en Vingtiéme Siécle. Revue d histoire, número 9, enero-marzo, 1986, p. 97-108.

VARELA PETITO, Gonzalo. Carlos Quijano y los Cuadernos de Marcha en México. EnDUTRÉNIT BIELOUS, Silvia y SERRANO MIGALLÓN, Fernando. (coord.).El exilio Uruguayo en México. México: Porrúa, 2008, p. 115-121.

YANKELEVICH, Pablo. Ráfagas de un exilio. Argentinos en México, 1974-1983. México: Colegio de México, 2009.

YANKELEVICH, Pablo; JENSEN, Silvina (comps.). Exilios. Destinos y experiencias bajo la dictadura militar. Buenos Aires: Libros del Zorzal, 2007.

\section{GANPHLAC}

Revista Eletrônica da ANPHLAC, ISSN 1679-1061, No. 19, p. 186-207, jul./dez., 2015. 